\title{
Thyroid Scintigraphy Findings in Patients Without Thyroid Tissue in the Ultrasonography
}

Güngör Taştekin1, Ahmet Kaya2, Buğra Sağlam3, Mustafa Kulaksızoğlu4, M. Emre Atabek5

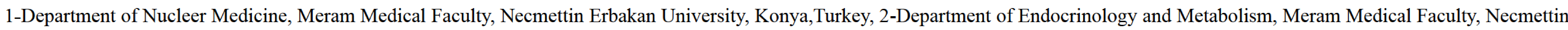
Erbakan University, Konya,Turkey, , 3-Department of Internal Medicine, Meram Medical Faculty, Necmettin Erbakan University, Konya,Turkey , 4-Department of Endocrinology and Metabolism, Meram Medical Faculty, Necmettin Erbakan University, Konya,Turkey, 5-Department of Pediatric Endocrinology and Metabolism, Meram Medical Faculty, Necmettin Erbakan University, Konya,Turkey

\section{INTRODUCTION}

Evaluation of the patients that was suspected to have thyroid agenesis were retrospectively evaluated.

\section{METHODS}

Totally 4155 patients had scintigraphy imaging between years of 2010-2015 in our university. $4021 \quad(96.77 \%)$ patients were adults (>18 years) and $134(3.22 \%)$ were in the pediatric population. Among adult population, 3060 (76.1\%) were female, and 1095 $(27.2 \%)$ were male. In the pediatric population, $85(63.4 \%)$ patients were girls and $49(36.5 \%)$ were boys.

\section{RESULTS}

Among 4155 patients, $15(0.36 \%)$ of them had no thyroid tissue in the ultrasonography. In the adult population 5 patients $(0.01 \%)$ were found to have thyroid agenesis in the ultrasonography whom 4 were women. Mean ages of the diagnosis was 22 years in the adult population. The oldest diagnosis was 50 years ago and the newest one was 4 years ago. In the patient with 50 years of history, USG appearence was minimal görüntü where as scintigraphcially substernal ectopic thyroid tissue. 3 patients scintigraphically at the tongue base, 1 patient sublingually.

In the pediatric group, 11 patients (8.95\%) were diagnosed as thyroid agenesis in the ultrasonography. 3 (33.3\%) of them were boys and $8(66.6 \%)$ were girls. Scintigraphic examination showed thyroglossal ectopic tissue in 1 patient, and in 10 patients, uptake was in the tongue base. 4 patients (36.6\%) were newly diagnosed hypothyroid patients, 7 patients $(63.3 \%)$ were on LT4 replacement therapy. TSH levels were evaluated in these patients $(96.3 \mathrm{mU} / \mathrm{L})$.

\section{CONCLUSIONS}

\section{REFERENCES}

Adult patients with hypothyroidism may have agenesis rarely but in the pediatric population it can be seen more frequently so it should be kept in mind especially in the newly diagnosed patients(1-2). 